\title{
Evaluation of different teaching-learning methods according to students' preference and perception
}

\author{
Maulin Mehta*, Sandeep Adwal, Ashutosh Chourishi
}

Department of Pharmacology, R.D. Gardi Medical College, Ujjain, Madhya Pradesh, India

Received: 16 November 2016 Accepted: 09 December 2016

*Correspondence to:

Dr. Maulin Mehta,

Email:

maulin_mehta@rediffmail.com

Copyright: (C) the author(s), publisher and licensee Medip Academy. This is an openaccess article distributed under the terms of the Creative Commons Attribution NonCommercial License, which permits unrestricted noncommercial use, distribution, and reproduction in any medium, provided the original work is properly cited.

\begin{abstract}
Background: Improved teaching methodology is prerequisite for education systems so that students learn effectively. The present study was done with the objectives of evaluation of different teaching-learning methods according to students' preference and perception.

Methods: It was observational, non-interventional questionnaire based study. Total 100 students were selected randomly from second MBBS as participants of it. They filled questionnaires with 11 questions, by selecting appropriate options.

Results: All students were interested in Pharmacology. Cardio-Vascular System and autocoids were the most interesting topics according to $40 \%$ of students. Total $53 \%$ of students preferred combination of chalk and board with PowerPoint presentation for understanding, while chalk and board alone $(65 \%)$ as more interactive teaching method. Total $80 \%$ of students preferred interactive lecture session. Clinical case/bed side study was preferred by $89 \%$ of students. Total $40 \%$ of students preferred combination of teachers' note and standard textbooks as reading materials. Total $80 \%$ of students mentioned that revision at the end of lecture is necessary. One and half year as ideal time to learn second MBBS, has been selected by $60 \%$ of students. Teaching with more clinical orientation is one of the changes suggested by $28 \%$ of students.

Conclusions: Combination of traditional chalk and board method with modern powerpoint method, wherever necessary, is ideal for interactive and understandable lecture session. Integration/correlation of clinical cases with clinical Pharmacology will be more helpful in understanding and learning. Proper and effective management of time is essential for maximum utilization of MBBS duration with optimum output for students.
\end{abstract}

Keywords: Chalk and board, Clinical case, PowerPoint, Teaching methodology

\section{INTRODUCTION}

Improved teaching methodology is prerequisite for education systems so that students can learn more effectively. In medical education system, we can enhance learning of MBBS students by integrating various teaching methods.

There are various teaching-learning methods practiced in our education system, like traditional Chalk and board, overhead projector, PowerPoint presentation or clinical case/bed side teaching, etc. All the methods have their own merits and demerits. Some of these methods will become only teacher-centered methods if it is noninteractive with students. Here such approach is least practical because the lecturer delivers lots of information without active involvement of students and without allowing them to apply it practically. As a result, students may lose both interest and understanding of the topic. So teacher-student interactive methods are more successful in improving students' performance. ${ }^{1}$ The main goal of ideal teaching learning method should be increased involvement, participation and interest of students and create active and self-directed learning.

Teaching skill is a difficult art to learn for becoming an effective teacher. Neil stated that defining an effective teacher involves two important components called "teacher's knowledge of the subject" and "skill in how to teach the subject". Teachers can develop teaching skills by years of teaching experience and also by getting feedback from students. 
Multiple researches indicate that students are the most qualified persons to report that whether the learning experience was productive or not. ${ }^{2}$ A meta-analysis of 41 research studies also supports the same and provides the strongest evidence of relationship between student ratings and student learning. ${ }^{3}$ So the present study was done with the objectives of evaluation of different teaching-learning methods according to students' preference and perception.

\section{METHODS}

The present study was observational, non-interventional questionnaire based study and done after getting ethical approval from institutional ethical committee. There were total 100 students selected randomly from all second MBBS batches as participants of the study. They were asked to fill questionnaires with 11 questions, which were prepared by taking guidance of few previously done similar studies in India., ${ }^{4,5}$ They have to fill the questionnaires by choosing an option to each question which they feel appropriate, irrespective of any particular topic or teacher. They can select more than one option, if they feel so. Written informed consents of the participants were taken and confidentiality was maintained at each level. The questionnaire used for the study purpose includes:

- Are you interested in pharmacology subject?

- Which subject is most interesting in second MBBS?

- Which is the most interesting topic in pharmacology?

- Which of the following teaching method is better in learning/understanding of topic?

- According to you, what type of lecture session should be done?

- Which of the following teaching method is more interactive?

- Is incorporation of clinical cases demonstration required for teaching clinical Pharmacology?

- What is your most preferred reading material?

- Revision at the end of lecture, required or not?

- How much time is adequate for second MBBS?

- What are the changes required according to you to make Pharmacology more interesting and understandable?

\section{RESULTS}

There were total 11 questions in the questionnaire answered by 100 randomly selected second MBBS students.

For the question regarding their interest in pharmacology, all of them (100\%) answered that they were interested in Pharmacology. In comparison with other second year subjects, total $60 \%$ of students have shown more interest in Pharmacology over the other subjects. In Pharmacology, both Cardio-Vascular System (CVS) and autocoids were most interesting topics according to total $40 \%$ of students. Here some of the students have chosen more than one topic (Figure 1).

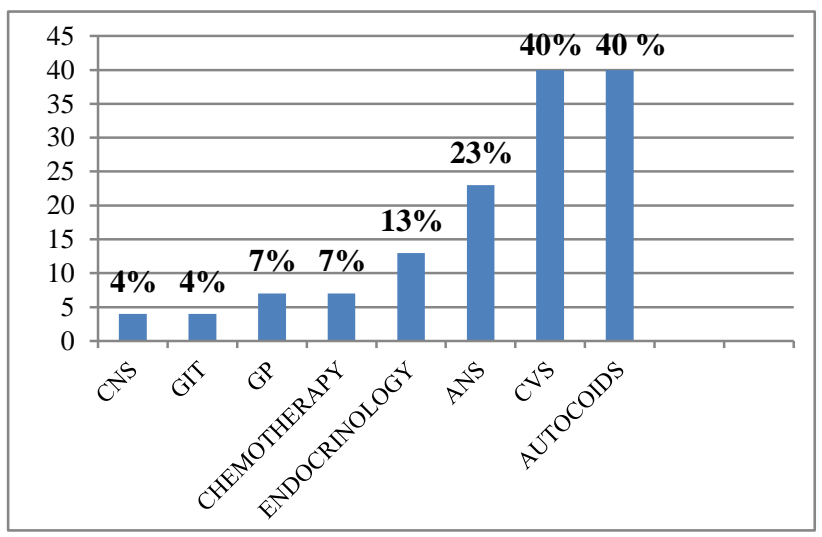

Figure 1: Interesting topics selected by students.

CNS: Central Nervous System, GIT: Gastro-Intestinal Tract, GP: General Pharmacology, ANS: Autonomic Nervous System, CVS: Cardio-Vascular System.

Total $53 \%$ of students preferred combination of chalk and board with PowerPoint presentation for learning and understanding, while chalk and board method alone $(65 \%)$ as more interactive teaching method than others (Figure 2). Total $80 \%$ of students have chosen interactive lecture as preferred lecture session over one way lecture.

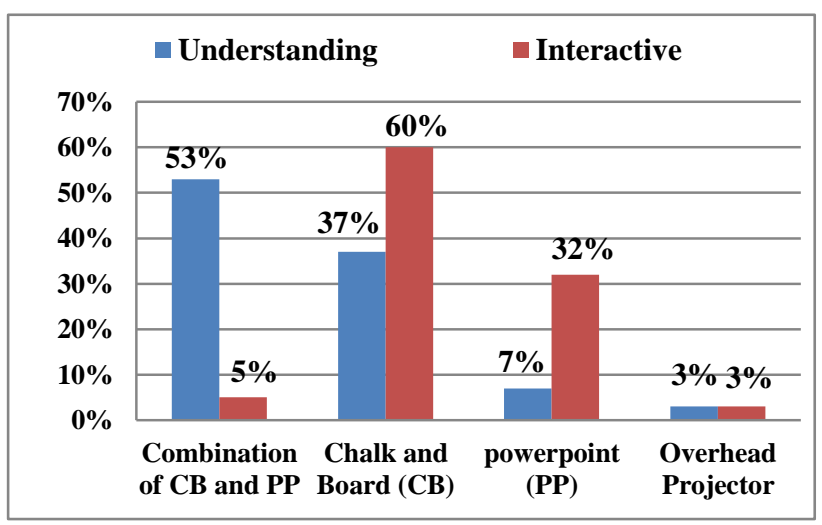

Figure 2: Preferred teaching method by students for both understanding and interaction.

There was total $89 \%$ of students mentioned incorporation of clinical case/bed side study for clinical Pharmacology as important requirement (Figure 3).

Total $40 \%$ of students preferred combination of teachers' note and standard textbooks as reading materials, followed by others (Table 1).

There were total $80 \%$ of students mentioned that revision at the end of lecture is necessary. Total $60 \%$ of students have chosen one and half year as ideal time to learn second MBBS, while remaining $40 \%$ preferred one year. 


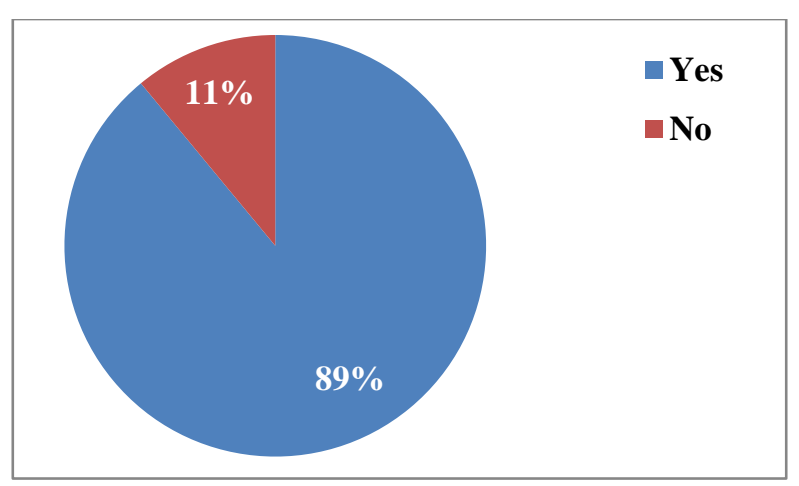

Figure 3: Incorporation of clinical case/bed side study for clinical Pharmacology.

Table 1: Preferred reading material.

\begin{tabular}{|ll|}
\hline Preferred reading materials & $\begin{array}{l}\text { Percentage of } \\
\text { students }\end{array}$ \\
\hline $\begin{array}{l}\text { Combination of Teahcers' notes and } \\
\text { Standard Textbooks }\end{array}$ & $40 \%$ \\
\hline Teachers' notes & $27 \%$ \\
\hline Standard Textbooks & $18 \%$ \\
\hline Self-prepared notes & $12 \%$ \\
\hline Small handbooks & $3 \%$ \\
\hline
\end{tabular}

In answer for question about changes required for making Pharmacology more interesting, total $28 \%$ of students have suggested teaching with more clinical orientation is better.

\section{DISCUSSION}

Medical education system is the base of ideal doctors and hence healthy society. It demands better teachers teaching with best methods to produce quality doctors from students. Many psychometric studies have revealed the close association between students' opinion and instructors' effectiveness. ${ }^{3,6}$

Interest in particular subject can affect understanding of it. In our study, all the students were interested in Pharmacology. So now it is our role to make teaching/lectures more interesting and understandable for students.

Result of this study has shown that Cardio-Vascular System (CVS) and autocoids are most interesting topics followed by Autonomic Nervous System (ANS), endocrine and others. It is seen that interesting topics are easy to understand, while more attention is required to learn difficult topics. We can make more interesting and interactive lectures for difficult topics to make them easily understandable.

With regard to teaching method, total $53 \%$ of students suggested that combination of Chalk and Board with PowerPoint presentation is better in learning/understanding, followed by Chalk and board alone $(37 \%)$. In other few studies done by Vikas Seth et al and Momi Baruah et al showing that powerpoint presentation is preferred over other methods. ${ }^{4}$ Our findings are not in accordance with their studies.

There are always few pros and cons associated with all teaching methods. In power point presentation, we can avoid the issues of complex diagram drawing, poor handwritings, and dirty blackboards seen with chalk and board methods. Few disadvantages associated with it are too much material, irrelevant images, and quick delivery of the lectures. ${ }^{7}$ So combination of both the methods, that is chalk and board and PowerPoint, for difficult diagrams, can become ideal solution to overcome this huddle.

There were total $89 \%$ of students suggesting incorporation of clinical case study along with clinical Pharmacology topic. Few other studies also support the demonstration of clinical case/bed side study with clinical pharmacology. ${ }^{5,8}$ It will allow the students to correlate more than one subject at a time and improve in understanding and learning.

In our study, most of the students preferred interactive teaching session over one way teaching. ${ }^{5}$ Similar finding came out with the study done by thirunavukkarasu et al. ${ }^{9}$ In one of the study, outcome reveals that most of the lecturer wanted to have interactions with the audience and put stress on some points when they felt that a particular diagram or point required amplification. ${ }^{7}$ For interactive lectures, students have preferred chalk and board method over PowerPoint presentation, in our study. It was very hard for lecturers to do interactive session with a 'rigid' electronic presentation format. ${ }^{7}$ In this regard, chalk and board is superior to PowerPoint presentation for interactive lecture sessions.

It is observed in the study that both teachers' notes and standard textbooks are preferred reading material for students. According to other study, the most effective lectures were ones where teachers' notes were supplied that could be annotated during the lecture. ${ }^{7}$ These efforts can be done to make teaching more feasible.

In the study, revision at the end of lecture is supported by majority of the students. Quick revision, at the end of the lecture, concerning the important points of topic will be helpful in memorizing and improving the learning of the students.

Last few questions in the questionnaire were not related with teaching methodology, but their outcome can affect the learning of students. Currently, the time duration of second MBBS, decided by MCI, is one and half year. Total $60 \%$ of the students, in our study, mentioned the same, while remaining $40 \%$ of the students wanted to be it of one year. It was published in the MCI: vision 2015, Undergraduate Medical Education, that "the course will 
be restructured as below to enable students to be more participatory and competent."

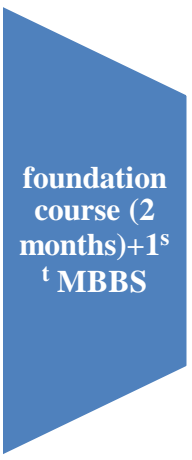

14 months

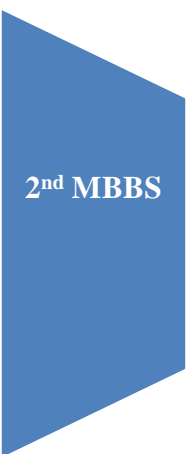

12 months

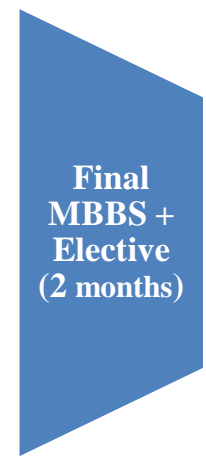

28 months*

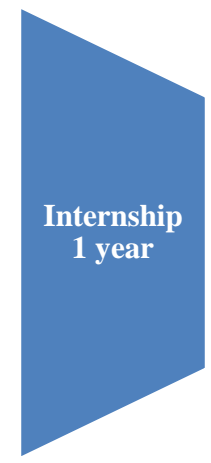

12 months
Figure 4: Course duration according to MCI vision 2015.

*wait period of 2 months should be allowed for preparation of NEET-PG. ${ }^{10}$

Proper management of MBBS time period, allows us to save the time with maximum output. So more feedback of students and teachers regarding this issue can be obtained by such future studies and appropriate modification can be done, accordingly.

One more interesting change in teaching methodology suggested by students is clinical orientation with paraclinical subjects. Integration of various subjects related with single topic and teach by particular subject-expert, will allow the students to correlate the topic with more clinical orientation.

Overall, this study was done with intention to improve teaching-learning methodology by obtaining students' perception. Main limitation of our study was small sample size and hence, such a study at national level will help us to gather ample number of data, which will lead us to a proper outcome.

\section{CONCLUSION}

Ideal teaching is the basic requirement of improved learning. Combination of traditional chalk and board method with modern PowerPoint method, wherever necessary, is ideal for interactive and understandable lecture session. More effort should be made to teach noninteresting difficult topics according to students' perspective. Integration/correlation of clinical cases with clinical Pharmacology will be more helpful in understanding and learning. Proper and effective management of time is essential for maximum utilization of MBBS duration with optimum output for students.

Funding: No funding sources

Conflict of interest: None declared

Ethical approval: The study was approved by the Institutional Ethics Committee

\section{REFERENCES}

1. Ganyaupfu EM. Teaching Methods and Students' Academic Performance. International Journal of Humanities and Social Science Invention. 2013;2(9):29-35.

2. Theall M., Franklin J. Students' ratings of Instruction: Issues for Improving Practice. New Directions for Teaching and Learning, no. 43. San Francisco: Jossey-Bass. 1990.

3. Gaubatz N. What's the Use of Student Ratings of Teaching Effectiveness? Available from: http://csti.syr.edu/csti.T-L/stdrate.htm.

4. Baruah M, Patel L. Evaluation of different teaching methods used in physiology lectures. Indian Journal of Basic and Applied Medical Research. 2014;4(1):271-76.

5. Chavda N, Yadav P. Second year students' feedback on teaching methodology and evaluation method in Pharmacology. National Journal of Physiology, Pharmacy and Pharmacology. 2011;1:23-31.

6. Dash SK, Patro S, Behera BK. Teaching methods and its efficacy, an evaluation by the students. J Indian Acad Forensic Med. 2013;35(4):321-24.

7. Shallcross DE, Harrison TG. Lectures: electronic presentations versus chalk and talk -achemist's view. Chemistry Education Research and Practice. 2007;8(1):73-9.

8. Kela AK, Mehta VL. Impact of inclusion of clinical projects in undergraduate teaching. Indian $\mathbf{J}$ Pharmacol. 1993;25:249-50.

9. Thirunavukkarasu J, Latha K, Sathish Babu C. A study on effectiveness of different teaching methodology in Pharmacology for under graduate students. Asian J Exp Biol Sci. 2011;2(3):487-92.

10. Medical Counsel of India. MCI: Vision 2015. March 2011;2:9-24. Available from: http://www.mciindia.org/tools/announcement/MCI_b ooklet.pdf

Cite this article as: Mehta M, Adwal S, Chourishi

A. Evaluation of different teaching-learning methods according to students' preference and perception. Int J Basic Clin Pharmacol 2017;6:76-9. 